\title{
Chinese Cause-related Marketing through Internet: Perceived Benefits, Participation, and Privacy Concerns
}

\author{
Qi Wang ${ }^{1}$ and Seong-Yeon Park ${ }^{2 *}$ \\ ${ }^{1}$ Student, School of Business, Ewha Woman's University, Seoul, Korea \\ ${ }^{2}$ Corresponding Author, Professor, School of Business, Ewha Woman's University, \\ Seoul, Korea \\ 1'wangqi9410@outlook.com, ${ }^{2}$ sypark@ewha.ac.kr
}

\begin{abstract}
With the growth of internet technology, cause-related marketing has become more diverse, therefore, it is of utmost importance to understand what kind of cause-related marketing campaigns consumers like. This study examines the impact of perceived benefits and privacy concerns on consumer participation in internet cause-related marketing. Through the questionnaire survey, 517 questionnaires have been divided into experienced groups and inexperienced groups. For those who have participated in internet cause-related marketing campaigns, the three types of perceived benefits (functional benefits, experiential benefits, symbolic benefits) can positively affect consumers' attitudes towards the campaign, then positively affect their participation. The privacy concerns have a significant negative moderating effect on the impact of functional benefits on attitudes and a significant positive moderating effect on the impact of symbolic benefits. For people who have not participated in internet cause-related marketing campaigns, only perceived symbolic benefits and experiential benefits can positively influence their attitudes towards the campaign. The privacy concerns have a significant positive moderating effect on the impact of symbolic benefits.
\end{abstract}

Keywords: Cause-related marketing, Consumer attitude, Consumer participation, Perceived benefits, Privacy concern

\section{Introduction}

Cause-related marketing is a representative practical method of corporate social responsibility, whose characteristic is to combine socially responsible activities with business activities to carry out co-value creation with consumers [1]. Because it can create both social value and economic value, cause-related marketing always attracts the wide attention of companies and scholars. However, when we observe cases on cause-related marketing, we find that not all of them are successful cases. It is necessary to construct a cause-related marketing strategy, which can guide consumers to produce good attitudes. Especially under the condition that the forms become more plentiful and consumers have more choices after cause-related marketing is combined with internet technology.

*This paper is recommended by February 2020 1st Domestic and International Integration Conference Article history:

Received (December 28, 2019), Review Result (January 30, 2020), Accepted (March 5, 2020) 
Existing Chinese researches about cause-related marketing have found that brand-cause fit, information reliability, customer trust can be important factors to influence consumer's attitude [2][3][4]. But to provide companies with a more comprehensive direction of development, it's necessary to investigate the effect of perceived benefits. Meanwhile, although consumer's privacy concerns about internet services have been considered as an important criterion for customized services [5]. It hasn't been mentioned in relevant to causerelated marketing.

This research discusses the influence of perceived benefits (functional, experiential, and symbolic) of internet cause-related marketing on consumer attitude and consumer participation, and the moderating effect of consumers' privacy concerns in this process. These tries can enrich researches relevant to cause-related marketing, have a deeper understanding of consumers' motives in participating in all kinds of cause-related marketing activities, and put forward some suggestions for companies to carry out cause-related marketing more efficiently.

\section{Theoretical background}

\subsection{Cause-related marketing}

According to the opinions of Varadarajan and Menon who are representative researchers of cause-related marketing, cause-related marketing refers to marketing activities of companies to donate a specified amount to a designated cause when consumers participate in companies' revenue-providing exchange activities [1].

Chinese researches on cause-related marketing can date back to 2002. Based on researches by Varadarajan and Menon, $\mathrm{Lu}$ and Li first came up with the concept of cause-related marketing in China and defined it as marketing activities that combine product distribution with public welfare [6]. After then, Gao pointed out the importance of cause-related marketing for China [7].

In 2012, China issued Charity Law, and then public welfare began to develop prosperously in China. In 2015, Premier Li Keqiang proposed the "Internet plus" strategy that all industries in China could actively combine internet technology [8]. Besides, up to June 2019, the number of Chinese netizens increased to 0.58 billion [9]. Meanwhile, young people are becoming new consumers in the Chinese public welfare industry [10]. So, a new type of cause-related marketing that can satisfy the needs of young people is necessary.

Under this background, the new form like Ant Forest which combines internet technology further develops cause-related marketing, and efficiently enhances consumers' initiative, successfully attracts young consumers. At the same time, Ant Forest also arouses a wave in academic circles from the aspect of new propaganda methods, new types of public welfare activity, and new methods to improve consumers' participation willingness [11][12][13].

This research aims to take benefits perceived by consumers in internet cause-related marketing as consumers' dominant motive to investigate how these benefits influence consumer attitude and participation in cause-related marketing.

\subsection{Perceived benefits}

Benefits refer to interests that consumer get from products or services [14]. When consumers consume products or services, they will endow a series of attributes with individual meaning and produce some subjective requirements or expectations [15]. There are many dimensions of perceived benefits. This research-based on the three dimensions put 
forward by Park, Jaworski, and MacInnis, investigates the relationship between perceived benefits and consumer attitude from functional, experiential, and symbolic benefits [16].

Functional benefits are defined as the benefits that help consumers solve or avoid problems they are faced with and they are the most essential benefits that consumers can get from products or services [14]. Experiential benefits not only conclude sensory satisfaction like happiness that consumers get when they consume products or services, but they also contain epistemic satisfaction with curiosity and thirst for knowledge [16]. Symbolic benefits refer to benefits that can satisfy consumers' internal requirements to improve themselves, promote their social status or express themselves into the group that they yearn for [14].

\subsection{Privacy concerns}

Schoeman defines privacy as the control of individuals over the degree of their personal information and private life available to others [17]. In a long term, companies have worked to improve their products and services through collecting customer information. However, consumers' increasingly weakened control force over their personal information is regarded as one of the risks of the internet, and consumers' privacy concerns have aroused wide attention in the network environment [18].

According to a survey of Chinese netizens in 2018, 85\% of Chinese netizens said that they were more alert to individual privacy than before. However, there are still $62 \%$ of interviewees who were willing to sell or provide their geographic position (53\%), browsing history (50\%), and other information for companies free of charge [19]. Therefore, it can be concluded that different degree of consumers' susceptibility to privacy will influence their attitudes towards internet cause-related marketing.

\section{Research model and hypothesis inference}

According to existing researches, it is much easier for convenient services to be used by consumers and this also makes it easier to improve consumers' satisfaction [19]. Meanwhile, convenience and effectiveness perceived on the internet can have positive effects on consumers' perceived value and consumption intentions [13]. As a result, the conclusion of this research is as follows.

H1: Perceived functional benefits of internet cause-related marketing will have a positive influence on consumers' attitudes towards internet cause-related marketing.

According to existing researches, sensory satisfaction and epistemic satisfaction are regarded as important factors that influence consumers' decisions as they can promote consumers to have good attitudes through arousing their positive emotions [20]. Therefore, the conclusion of this research is as follows.

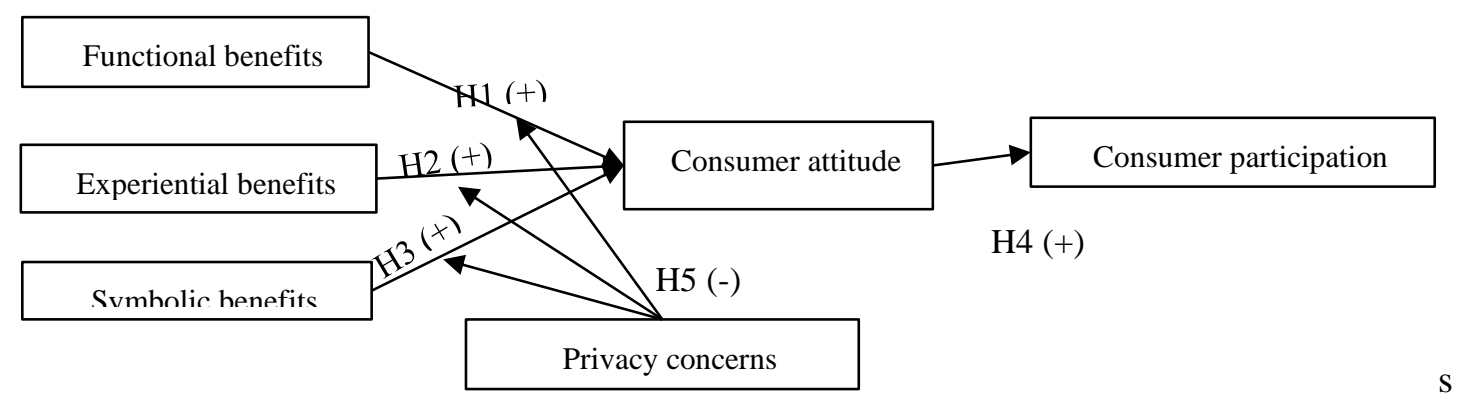


Figure 1. Research model

H2: Perceived experiential benefits of internet cause-related marketing will positively influence consumers' attitudes towards internet cause-related marketing.

The researches on green consumption and ethical fashion have shown that efficiently showing oneself and getting others' admiration can positively influence consumers' attitudes [21][22]. Therefore, the conclusion of this research is as follows.

H3: Perceived symbolic benefits of internet cause-related marketing will positively influence consumers' attitudes towards internet cause-related marketing.

The researches in the field of consumer behaviors show that attitudes are closely related to purchasing intentions, purchasing behaviors, and recommendation intentions [23]. Therefore, this research concludes that the more positive attitudes consumers have, the stronger willingness and deeper participation they will have.

H4: Consumers' friendly attitude towards internet cause-related marketing will have a positive influence on their participation/ participation intentions to internet cause-related marketing.

When people perceive the privacy risk of products or services, they will have negative emotions and reduce acceptability to the products [24]. Therefore, this research gets the conclusion that the positive influence of perceived benefits on attitudes will probably reduce because of privacy concerns.

H5: Consumers' privacy concerns will have a negative moderating influence on the relationship between perceived benefits of internet cause-related marketing and consumers' attitudes.

H5-1: Consumers' privacy concerns will reduce the positive influence of perceived functional benefits on consumers' attitudes.

H5-2: Consumers' privacy concerns will reduce the positive influence of perceived experiential benefits on consumers' attitudes.

H5-3: Consumers' privacy concerns will reduce the positive influence of perceived symbolic benefits on consumers' attitudes.

\section{Results}

In this research, we investigated consumers who have participated in and have not participated in internet cause-related marketing activities. The questionnaire includes questions to measure perceived benefits (functional, experiential, symbolic), privacy concerns, consumer attitude, and consumer participation, questions relevant to demographic statistics, and questions to master characteristics of consumers who participate in internet cause-related marketing activities.

Through the online questionnaire survey, a total of 535 questionnaires have been collected in this study. After removing 18 invalid questionnaires, 517 questionnaires have finally been used for analysis. According to whether consumers have participated in online cause-related marketing campaigns, the questionnaire has been divided into experienced groups and inexperienced groups. The inspection results of the two groups are as follows.

In the group of experienced interviewers, three perceived benefits all have a positive influence on consumers' attitudes and participation with statistical significance. Therefore, the hypothesis 1, 2, 3 and 4 are all supported [Table 1]. In the group of inexperienced 
interviewees, hypothesis 1 is refused, and hypotheses 2, 3, and 4 are supported [Table 2]. Meanwhile, both the two groups find perceived experiential benefits are the most influential.

Table 1. Result (experienced group)

\begin{tabular}{|c|c|c|c|c|c|c|}
\hline Independent variables & Dependent variables & Estimate & S.E. & C.R. & $\mathrm{P}$ & Result \\
\hline Functional benefits & \multirow{3}{*}{ Attitude } & 0.248 & 0.117 & 1.927 & 0.034 & H1 support \\
\hline Experiential benefits & & 0.579 & 0.135 & 4.716 & 0.000 & H2 support \\
\hline Symbolic benefits & & 0.136 & 0.026 & 5.121 & 0.000 & H3 support \\
\hline Attitude & Participation & 1.034 & 0.087 & 11.854 & 0.000 & H4 support \\
\hline
\end{tabular}

Table 2. Result (inexperienced group)

\begin{tabular}{|c|c|c|c|c|c|c|}
\hline Independent variables & Dependent variables & Estimate & S.E. & C.R. & $P$ & Result \\
\hline Functional benefits & \multirow{3}{*}{ Attitude } & 0.076 & 0.109 & 0.697 & 0.486 & H1 refuse \\
\hline Experiential benefits & & 0.453 & 0.073 & 6.247 & 0.000 & H2 support \\
\hline Symbolic benefits & & 0.218 & 0.071 & 3.072 & 0.002 & H3 support \\
\hline Attitude & Participate intention & 0.243 & 0.066 & 3.668 & 0.000 & H4 support \\
\hline
\end{tabular}

The inspection results of privacy concerns' moderating effects are as follows. In the experienced group, privacy concerns have a significant negative moderating effect on the impact of functional benefits on attitudes and a significant positive moderating effect on the impact of symbolic benefits on attitudes. That is, privacy concerns weaken the impact of perceived functional benefits, but strengthen the impact of perceived symbolic benefits on consumer attitudes. In the group of inexperienced interviewees, no obvious moderating effect on functional and experiential benefits is showed and the influence on symbolic benefits shows significant potentiation which is different from the hypothesis.

\section{Discussion}

To have a deeper understanding of consumers' participation in internet cause-related marketing, this research examined the influence of perceived benefits and privacy concerns on consumers' attitudes and participation/participation intentions.

The theoretical significance of this study is as follows. Firstly, factors that influence Chinese consumer participation in internet cause-related marketing campaigns have been studied and related research on cause-related marketing has been enriched in this study. This study identifies three perceived benefits based on Park, Jaworski, and Mac Innis's perceived benefits theories and considers how these affect consumer attitudes and participation [16]. Secondly, the role of privacy concerns of Chinese consumers in internet cause-related marketing activities has been explored in this study. Although more and more companies attempt to implement a variety of personalized services, it's important to consider whether consumers will accept such services. This study is meaningful in that it identifies the role of consumer privacy concerns in internet cause-related marketing.

The practical significance of this research is as follows. First, companies can effectively promote consumers' participation by satisfying their functional, experiential, symbolic needs. In China, more and more young people show great interest in public welfare, hence, it is necessary to develop a new cause-related marketing campaign to attract young consumers. Second, when collecting the personal information of consumers, companies should pay attention to the issue of information leakage and improve consumer trust. 
Here are the limitations of this study. Firstly, the questionnaire of this study has been implemented for Chinese consumers, so there are some shortcomings in the generality of the results. Secondly, the relationship between privacy concerns and perceived benefits is not clear enough and it's worth looking forward to some discoveries about it.

\section{References}

[1] P. R. Varadarajan and A. Menon, "Cause-related marketing: A coalignment of marketing strategy and corporate philanthropy," Journal of Marketing, vol.52, no.3, pp.58-74, (1988) DOI: 10.1177/002224298805200306

[2] J. F. Fan and Z. L. Tian, "Research on the influence of the matching between brand and cause on the effect of cause-related marketing," Contemporary Economy and Management, vol.32, no.1, pp.18-22, (2010) DOI: 10.13253/j.cnki.ddjjgl.2010.01.008

[3] X. M. Ren, "Research of relationship among information quality characteristics, consumer involvement and purchase intention," Journal of Wuhan Business University, vol.30, no.3, pp.54-58, (2016) DOI: 10.16199/j.cnki.jwbu.2016.03.014

[4] K. Z. Yu, L. Chen, and Y. F. Yu, "A research of the influence of customer trust on behavior intention in cause-related marketing," Economic Survey, no.9, pp.124-127, (2009) DOI: 10.15931/j.cnki.10061096.2009.05.020

[5] J. T. Liu and L. D. Zhu, "The influence of consumer privacy concern on collaborative consumption willingness in sharing economy - An empirical study based on didi chuxing platform," Journal of Fujian Business University, no.6, pp.34-40 ， (2019) DOI: 10.19473/j.cnki.1008-4940.2019.06.005

[6] T. H. Lu and W. R. Li, "New way of marketing: Cause-related marketing," Business management journal, no.9, pp.58-60, (2002) DOI: 10.19616/j.cnki.bmj.2002.09.017

[7] Y. Q. Gao, "The cause-related marketing of Chinese enterprises, contemporary economy and management," no.04, pp.37-40, (2007) DOI: 10.13253/j.cnki.ddjjgl.2007.04.014

[8] Innovation is everywhere, "Internet plus: China's official strategy for the uberisation of the economy," https://www.innovationiseverywhere.com/internet-plus-chinas-official-strategy-for-the-uberisation-of-theeconomy/, (2015)

[9] Cyberspace Administration of China, "China's 44th statistical report on internet development," http://www.cac.gov.cn/2019-08/30/c_1124938750.htm, (2019)

[10] Cnfina, "Young people's public welfare: Public welfare innovation of ifeng.com," http://www.cnfina.com/kuaixun/20170518_102948.html, (2017)

[11] Y. Hu and X. M. Zhang, "Gamification innovation strategy of environmental communication in the Internet environment,” Journalism Lover, no.02, pp.77-79, (2018) DOI: 10.16017/j.cnki.xwahz.2018.02.019

[12] $\mathrm{S}$. $\mathrm{Hu}$, "The influence of online public welfare on behavior and values of youth-taking ant forest as an example," The Guide of Science and Education, no.5, pp.148-149, (2018) DOI: 10.16400/j.cnki.kjdkx.2018.05.068

[13] J. T. Zhu and S. J. Zhang, "Research on improving users' participation in network Cause-related marketing," Journal of Zhengzhou University of Aeronautics, vol.36, no.4, pp.61-69, (2018) DOI: 10.19327/j.cnki.zuaxb.1007-9734.2018.04.007

[14] K. L. Keller, "Conceptualizing, measuring, and managing customer-based brand equity," Journal of marketing, vol.57, no.1, pp.1-22, (1993) DOI: 10.1177/002224299305700101

[15] J. P. Peter and J. C. Olson, “Consumer behavior: marketing strategy perspectives,” Irwin Inc., Homewood , pp.36-66, (1987)

[16] C. W. Park, B. J. Jaworski, and D. J. MacInnis, "Strategic brand concept-image Management," Journal of marketing, vol.50, no.4, pp.135-145, (1986) DOI:10.2307/1251291 
[17] F. D. Schoeman, "Philosophical dimensions of privacy: an anthology," Cambridge University Press , New York, pp.75-103 (1984)

[18] Norton, "2018 Norton LifeLock cyber safety insights report," https://us.norton.com/cyber-security-insights2018, (2019)

[19] J. W. Jung and S. Y. Cho, "Relationship among perceived benefit, perceived risk and continuous use of user' Internet primary bank: The mediation effects of trust," Journal of the Korea Convergence Society, vol.9, no.12, pp.195-205, (2018) DOI: 10.152 07/JKCS.2018.9.12.195

[20] R. Batra and O. T. Ahtola, "Sources of the hedonic and utilitarian measuring attitudes consumer," Marketing Letters, vol.2, no.2, pp.159-170, (1991) DOI: 10.1007/BF00436035

[21] J. J. Yoo, L. Divita, and H. Y. Kim, "Environmental awareness on bamboo product purchase intentions: do consumption values impact green consumption," International Journal of Fashion Design Technology and Education, vol.6, no.1, pp.27-34, (2013) DOI: 10.1080/17543266.2012.758318

[22] H. K. Moon, H. J. Choo, H. S. Park, and E. S. Baek, "The roles of benefit and risk perception in ethical fashion consumption," Journal of the Korean Society of Clothing and Textiles, vol.37, no.2, pp.159-173, (2013) DOI:10.5850/JKSCT.2013.37.2.159

[23] W. Boulding, A. Kalra, R. Staelin, and V. A. Zeithaml, "A dynamic process model of service quality: from expectations to behavioral intentions," Journal of marketing research, vol.30, no.1, pp.7-27, (1993) DOI: $10.2307 / 3172510$

[24] M. C. Lee, "Factors influencing the adoption of internet banking: An integration of TAM and TPB with perceived risk and perceived benefit," Electronic commerce research and applications, vol.8, no.3, pp.130141, (2009) DOI: 10.1016/j.elerap.2008.11.006 
This page is empty by intention. 